\title{
Overview of Water and Fertilizer Integration Development
}

\author{
Huaiguo Zheng ${ }^{a}$, Limin Chuan ${ }^{b, *}$, Jingjuan Zhao ${ }^{c}$, Sufen Sun ${ }^{d}$ and Junfeng \\ Zhang $^{\mathrm{e}}$
}

\author{
Institute of Information on Science and Technology of Agriculture, Beijing Academy of Agriculture \\ and Forestry Sciences, Beijing, 100097, China

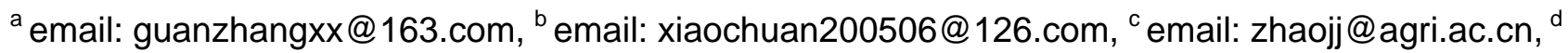 \\ email: sunsf@agri.ac.cn, ${ }^{\mathrm{e}}$ email: zhangjf@agri.ac.cn, * corresponding author.
}

Keywords: Agricultural water, Fertilizer application, Fertigation, Develop status, China

Abstract. Fertigation (Integrated management of water and fertilizer) aims to control irrigation water and nutrient application comprehensively according to crop requirements, in order to promote fertilizer nutrients uptake by water, and to enhance water and nutrient use efficiency in farmland. This paper analyzed the necessary development of fertigation, reviewed the develop status of fertigation in China and other countries, and to show the extension technologies in the world. It is suggested that fertigation is an important way to promote the efficient use of water and fertilizer resources.

\section{Introduction}

Fertigation (integrated management of water and fertilizer) aims to control irrigation water and nutrient application comprehensively integrated according to crop requirements, in order to promote fertilizer nutrients uptake by water, and to enhance water and nutrient use efficiency in farmland. Compared with the traditional mode, fertigation is a revolutionary transformation of the management of water and fertilizer. It transformed the canal to pipeline, change the sense of irrigate soil to irrigate crops, turn soil fertilization to crop fertilization, and convert water and fertilizer separate to integration. At the same time, fertigation could improve water and fertilizer use efficiency, save labor and economy, improve the land utilization and ensure balanced nutrient supply, also contribute to environment protection, improve soil conditions, and increase the yield and quality of agricultural products.

The integration of water and fertilizer is the need to change the way of agricultural development. The modern agriculture should first change the develop mode, make effort to improve water and fertilizer use efficiency, and to break through the water and fertilizer resource constraints to achieve sustainable development ${ }^{[1]}$.

To promote China's fertilizer integration technology research and further development, the Ministry of Agriculture claims that agricultural water saving is one of the focal points of work. It issued the guiding opinions on integration technology of water and fertilizer, and pointed out that by 2015, the promotion area of fertilizer integration should run up to more than 5.33 million ha, and put forward solutions for existing problems in the application, and proposed suggestions for the assignment in future work. The integration of water and fertilizer technology becomes the main extension technology in China's construction for high yield and high efficient agriculture, showing an unprecedented development opportunity ${ }^{[2]}$. At the same time, the relevant research institutions should also strengthen the joint of different disciplines, making full use of research resources, to analyze the transformation characteristics of different crop nutrient and root layer regulation technology, then integrated high yield and high efficiency fertilizer integration technology and related equipment; the equipment producer and service providers, should strengthen communication and cooperation between scientific research institutes, and to make innovations on fertilizer synergistic technology and product development, also focus on key technology research and application of fertilizer integration automation and information technology, to ensure the actual needs of the integration of water and fertilizer development, to promote the integration technology of China's application in agricultural production ${ }^{[3]}$. 


\section{Fertigation Development in Foreign Countries}

Britain. The integration of water and fertilizer originated in soilless culture, and with the development of efficient irrigation technology to develop. At the end of eighteenth Century, John Woodward, who was from Britain, made the plant grown in soil extract water, which is the first integration of water and fertilizer cultivation. The first test of trickle irrigation technology in the world can be traced back to the 19th century, but really originated from the early 1950s and 1960s. In the 1970s, due to mass production of cheap plastic pipe, it greatly promoted the trickle irrigation and micro irrigation systems development, including drip irrigation, micro spray irrigation and micro sprinkler irrigation, and in the past 40 years, fertilizer integration technology in the world has a rapid development ${ }^{[1]}$.

United States. In 1913, the United States built the first drip irrigation project, which is the largest country of micro irrigation area currently in the world. There were $60 \%$ of potatoes, $25 \%$ corn, 33\% of the fruit trees in irrigated agriculture are used fertilizer integration technology. The new type of water soluble fertilizer and pesticide injection control device were development and applied in agriculture, and the special fertilizer used for fertigation was accounted for $38 \%$ of the total amount. The United States has arranged a variety of water-saving irrigation systems. For example, California has established a perfect integration of water and fertilizer facilities and service system, of which $50 \%$ of the total area adopting sprinkler, $43 \%$ for surface irrigation, $6 \%$ for drip irrigation, and $1 \%$ for other instruments. Fixed sprinkler irrigation and mobile sprinkler irrigation, of which $80 \%$ for axial movable sprinkler irrigation. Drip irrigation area is increasing year by year, and the most effective irrigation method is under plastic film drip.

Germany. Germany made the water flow to soil from a hole, which was a breakthrough in 1920. After the rise of the plastics industry in the 1950s, more efficient irrigation technology has been rapid development, and irrigation and fertilization soon be combined, and formed a new agricultural technology with high precision control of soil moisture and nutrient.

Netherlands. Since the early 1950s in Netherlands, the number of greenhouse slowly increased, and the liquid fertilizer used for irrigation system also has increased significantly. With that, the pump for precise nutrient supply of fertilizer and mixing tank has been developed.

Australia. In recent years, fertilizer integration technology in Australia developed rapidly. Australia allocated a total of $\$ 100$ billion for national water safety plan in 2006 and 2007, for development of irrigation facilities and fertilizer integration technology, and the establishment of soil moisture monitoring system used to guide irrigation and fertilization.

Israel. Israel has experienced several periods of agricultural irrigation, i.e., flood irrigation, furrow irrigation, sprinkler irrigation, drip irrigation and other development stages. Since the beginning of the sixties of the 20th century, irrigation and fertilization technology became popular. The national water supply system for irrigation and fertilizer application was built in 1964. More than half of the arable land in the country is applied to the irrigation and fertilization system, including fruit trees, flowers, greenhouse crops, field vegetables and field crops. At the beginning of the eighties of the 20th century, the irrigation and fertilization technology in Israeli turned to automatic propelling machine irrigation system, and fertilization system combined the fertilizer tank, a venturi vacuum pump and hydraulic driven fertilizer syringe together, and introduced computer control technology and equipment, make the nutrient distribution more uniformity. Israelis actively develop and promote water-saving technologies and equipment, in order to use a small amount of water to meet the needs of the crops in sandy land, and put forward the idea of "watering crops instead of watering the soil". At present, Israel each year introduced and extended new technologies and equipment for drip irrigation, and from the drip irrigation technology derived buried irrigation, sprinkler irrigation, distributed irrigation etc., some of these technologies have been adopted by China and other international market ${ }^{[4]}$.

India. India has introduced the micro irrigation technology since 1981, and began to develop a larger scale after 1986. Now micro irrigation area in India has reached 26 million hectares. The government of India developed micro irrigation development grant program in 1992-1997, and state subsidies of 
horticultural crops irrigation system with a total investment of $90 \%$, about 4950 yuan per hectare. In the "eight five" period, the government of India invest \$280 million to irrigation project. In order to protect and promote the orchard development, some states implemented the orchard irrigation assistance plan, and thus to promote the rapid development of micro irrigation technology. At present, India has more than 70 different sizes of micro irrigation equipment manufacturers, which the five largest equipment manufacturers accounted for $78 \%$ of total market sales. India also exports irrigation equipment to Sri Lanka and the Middle East, and the annual total exports accounted for $10 \%-15 \%$ of total output ${ }^{[5]}$. In India, many public agricultural university and National Agricultural Research Institute have done much research on micro irrigation technology and development, and held many short term training courses for agricultural water conservancy officials and farmers. Also the government used a variety of media play to promote drip irrigation technology extension.

In addition, Italy, Spain, France, Japan, South Africa and other countries also has the rapid development of fertilizer integration technology. According to the Sixth International micro assembly information, the micro irrigation area increased 633\% from 1981 to 2000, with an average annual increased by 33\%, and up to 373.33 million $\mathrm{hm}^{2}$, most of which used fertilizer integration technology. Entering the new century, fertilizer integration technology development more rapidly and further expand the application area. In addition, the various water soluble fertilizer development and production has made great progress, which matched with the water and fertilizer integration. Another is, some developed countries have formed a perfect equipment production, the allocation of fertilizer and promotion service system.

\section{Fertigation Development in China}

China started research on integration technology of water and fertilizer from 1975. At that time, China introduced the drip irrigation equipment from Mexico, and established 3 experimental sites with an area of $5.3 \mathrm{hm}^{2}$, and has achieved significant increase effect on production and water saving. In 1977, Xinjiang Academy of Agricultural Science reclamation scientific learning experience from Israel, and purchased drip irrigation equipment to carry out the drip irrigation experiment for vegetables, fruits and other horticultural crops. The results showed that drip irrigation technology had an important effect on water-saving and yield increasing, also helped to save labor and economy. The first generation of drip irrigation equipment was successful development and produced in our country in 1980. After 1981, based on the introduction of foreign advanced production technology, the scale production of irrigation equipment in China has gradually formed, and gradually developed into a large area form the experiment and demonstration.

From the middle of 1990s, the theory and application technology of the irrigation fertilization have been paid more and more attention. The Ministry of Agriculture started the organization and implementation of water-saving agricultural project in 2002, established demonstration area of fertilizer integration technology. China formulated work plans for water-saving, i.e. the national agricultural water-saving program (2012-2020), the development principles concerning promoting the farmland water-saving work opinions, the national farmland water-saving demonstration program, and the guiding opinions on fertilizer integration technology. The government adheres to the develop principles of the amount of water limited, ecological priority, quality and efficiency improved, farmers' income increase, also integrated various funds and increase investment, effectively promoted the popularization of fertilizer integration technology, and achieved remarkable results.

The application scale continues to expand. Since 2002, the Ministry of Agriculture implemented national dryland farming and water saving projects, and invested a total of more than 1 billion yuan, to set up fertilizer integration technology of core demonstration area of 3.33 million $\mathrm{hm}^{2}$ in more than 20 provinces, focused on experimental demonstration and technical integration, which covering more than 20 kinds of crops, effectively promoted the popularization and application of the integration technique of water and fertilizer. At present, the technology has been expanded in nearly 30 provinces, and the fertigation has applied by extended to wheat, corn, potato, soybean and other crops, and the expanded application area was 266.7 million $\mathrm{hm}^{2}$ each year ${ }^{[6]}$. 
Continuous innovation of technology model. According to the principle of suiting measures to local conditions, following the crop water requirement rules and water resource conditions and characteristics of the equipment, the government carried out technology integration, and formed a series of fertilizer integration technology mode. Divided according to the region, there were arid and semi arid region of membrane drip irrigation, hilly gravity drip irrigation and fertigation, plain micro spray water and fertilizer integration mode; divided by the equipment, there were mobile micro irrigation and fertilization integration mode, full automatic intelligent integration patterns of water and fertilizer, small simple self-service fertilizer integration mode. According to the condition of facilities, there were general field fertilizer integration mode, greenhouse film surface set rain water and fertilizer integration mode and so on.

Continuous improvement of technical products. With the popularization and application of fertilizer integration technology, constantly reinforce the foundation work, and constantly improve the technology related products. The soil moisture monitoring method and equipment were also developed, and it can quickly obtained the soil moisture status, in order to laid the foundation for soil moisture precise management; through a series of experiments carried out in different regions and different crops, it could observed a large number of micro irrigation conditions irrigation and fertilization technology parameters, and make pattern optimization, compile technical data, for water and fertilizer to promote the integration of technology application provides scientific basis; a variety of spray and drip irrigation pipe (belt), filtering and fertilizing equipment product is becoming more and more mature, expand the scope of application, continuously improve the durability, strongly support the integrated development of water and fertilizer. Water soluble fertilizer research and development aspects breakthrough, for micro irrigation water soluble fertilizer varieties are constantly emerging, provide supporting agricultural fertilizer integration technology popularization and application.

To optimize the promotion mechanism. In the experimental demonstration and extension work for many years, the integration of water and fertilizer technology promotion mechanism has been explored. Governments promote the model by their investment and technical subsidies, in order to promote the fertigation application. Technology driven mode, through the technical promotion department to carry out the demonstration and training of technical to promote the application. Enterprise pulling mode, through relevant enterprises to carry out equipment products distribution activities, for farmers to provide products and services, technology combined pull applied; professional cooperative organizations of farmers driving mode. To all types of specialized farmer cooperatives as the carrier, promote organized and standardized production and technology popularization and application ${ }^{[7]}$.

Input costs significantly reduced. Through the focus on research related equipment, optimizing the integration of water and fertilizer system design and development of micro irrigation water soluble fertilizer, the basic realization of the localization of fertilizer integration related facilities, equipment and products, dramatically reducing the cost of inputs. Input equipment and facilities have been from 2000 to 3000 yuan $/ 667 \mathrm{~m}^{2}$ significantly reduced to 800 yuan $/ 667 \mathrm{~m}^{2}$, efficient water soluble fertilizer reduced from 20000 yuan per ton to 1 million yuan per ton, fertigation began from high-end aristocrat technologies to civilian applications development, from agricultural facilities to field application, from vegetables, fruit trees, cotton, and other economic crops development to wheat, corn, potato and other crops.

\section{Summary}

It is suggested that fertigation is the important way to promote the efficient use of water and fertilizer resources. China should pay more attention to develop the fertigation technology, in order to make full use of the water and fertilizers. 


\section{Acknowledgements}

Funding for this research is provided by the Innovation Program of Beijing Academy of Agricultural and Forestry Sciences "Information research to promote the agricultural science and technology innovation ability" and "Structure evolution and driving forces analysis of agricultural water use in Beijing”.

\section{References}

[1] X.Z. Gao, S. Du, Y.H. Zhong, Y. Wu, and G. Zhang. Present situation and Prospect of the integrated development of water and fertilizer. China Agricultural Information, Vol. 02 (2015), p. 14-19, 63.

[2] Information on http://www.moa.gov.cn/zwllm/zwdt/201303/t20130304_3236967.htm

[3] G.F. Chen, S. Du, R.F. Jiang, X.Z. Gao. The present situation of research and application of water and fertilizer integration technology in our country. China Agricultural Technology Extension, Vol. 05 (2013), p. 39-41.

[4] Y. M. Li, J. Ren, H.T. Liu, L.C. Wang. Introduction and Enlightenment of Fertigation in Israel. Journal of Jilin Agricultural Sciences, Vol. 39(2014), p:91-93.

[5] L.L. Yang, H.W. Zhang, M.Q. Han, C.Z. Wang and S.M. Yang. Analysis of Techniques and Application Prospect of Water and Fertilizer Integration Technology. Journal of Anhui Agri. Sci., Vol. 43(2015), p: 13-25, 28.

[6] P. Gao, H.Z. Jian, Y. Wei, W. He, X.F. Wang. The Application Status and Development Prospect of Integrative Water and Fertilizer. Modern agricultural science and technology, Vol. 8 (2012), p: 250, 257.

[7] J. Zhao. The problems and solutions in the adaption of fertigation technology. Northwest A\& F University, 2015. 